\title{
Amycolatopsis thermophila sp. nov. and Amycolatopsis viridis sp. nov., thermophilic actinomycetes isolated from arid soil
}

\author{
Correspondence \\ Michael Goodfellow \\ m.goodfellow@ncl.ac.uk
}

\author{
Tiago Domingues Zucchi, ${ }^{1,2}$ Geok Yuan Annie Tan ${ }^{1,3}$ \\ and Michael Goodfellow ${ }^{1}$
${ }^{1}$ School of Biology, University of Newcastle, Newcastle upon Tyne NE1 7RU, UK
${ }^{2}$ Departamento de Entomologia \& Acarologia, ESALQ, Universidade de São Paulo, Piracicaba, Brazil
${ }^{3}$ Institute of Biological Sciences, Faculty of Science, University of Malaya, 50603 Kuala Lumpur, Malaysia

\begin{abstract}
The taxonomic positions of two thermophilic actinomycetes isolated from an arid Australian soil sample were established based on an investigation using a polyphasic taxonomic approach. The organisms had chemical and morphological properties typical of members of the genus Amycolatopsis and formed distinct phyletic lines in the Amycolatopsis methanolica 16S rRNA subclade. The two organisms were distinguished from one another and from the type strains of related species of the genus Amycolatopsis using a range of phenotypic properties. Based on the combined genotypic and phenotypic data, it is proposed that the two isolates be classified in the genus Amycolatopsis as Amycolatopsis thermophila sp. nov. (type strain $\mathrm{GY} 088^{\top}=\mathrm{NCIMB}$ $14699^{\top}=\mathrm{NRRL} \mathrm{B}-24836^{\mathrm{T}}$ ) and Amycolatopsis viridis sp. nov. (type strain $\mathrm{GY} 115^{\top}=\mathrm{NCIMB}$ $14700^{\top}=$ NRRL B-24837 ${ }^{\top}$ ).
\end{abstract}

The genus Amycolatopsis Lechevalier et al. 1986, a member of the family Pseudonocardiaceae, can be distinguished from other genera classified in this taxon by using genusspecific oligonucleotide primers based on 16S rRNA gene sequences (Tan et al., 2006a) and by a combination of chemotaxonomic and morphological properties (Labeda et al., 2011). At the time of writing, the genus contains 45 species with validly published names, although there are strong grounds for believing that it is grossly underspeciated (Tan et al., 2006a). The genus encompasses alkaliphilic, halophilic, mesophilic and thermophilic species that can be distinguished using a combination of phenotypic properties (Goodfellow et al., 2001; Labeda et al., 2003; Tan et al., 2007). These taxa fall into several multi- and singlemembered subclades in the Amycolatopsis 16S rRNA gene tree (Tseng et al., 2006; Bian et al., 2009; Lee, 2009). The thermophilic species form a distinct phyletic line, the Amycolatopsis methanolica subclade, which also encompasses Amycolatopsis eurytherma, Amycolatopsis thermoflava and Amycolatopsis tucumanensis (Chun et al., 1999; Kim et al., 2002; Albarracín et al., 2010).

The current classification of the genus Amycolatopsis provides a sound basis for the delineation of additional

The GenBank/EMBL/DDBJ accession numbers for the 16S rRNA gene sequences of Amycolatopsis thermophila $\mathrm{GYO}^{\top} 8^{\top}$ and Amycolatopsis viridis GY $115^{\top}$ are AY129774 and AF466095, respectively. species, as shown by the description of novel species of clinical (Labeda et al., 2003; Huang et al., 2004), ecological (Albarracín et al., 2010; Bian et al., 2009) and biotechnological (Wink et al., 2003; Tan et al., 2007) interest. The present study, conducted using a polyphasic approach, was designed to establish the taxonomic status of two strains that were isolated from a composite arid Australian soil sample and found to form distinct phyletic lines in the 16S rRNA A. methanolica subclade (Tan et al., 2006a). The strains, isolates $\mathrm{GY} 088^{\mathrm{T}}$ and $\mathrm{GY} 115^{\mathrm{T}}$, exhibited a range of properties consistent with their recognition as two separate novel species of the genus Amycolatopsis.

Isolates $\mathrm{GY} 088^{\mathrm{T}}$ and $\mathrm{GY} 115^{\mathrm{T}}$ were isolated from SM1 and SM2 agar plates (Tan et al., 2006a), respectively, which had been inoculated with a suspension of an arid composite Australian soil sample and incubated at $28{ }^{\circ} \mathrm{C}$ for 21 days. The strains were maintained on plates of modified Bennett's agar (Jones, 1949) at room temperature and as suspensions of mycelia fragments in glycerol $(20 \%, \mathrm{v} / \mathrm{v})$ at $-20{ }^{\circ} \mathrm{C}$. Biomass for the chemotaxonomic and molecular systematic studies was prepared by harvesting from shake flasks of glucose-yeast extract (GYE) broth (Gordon \& Mihm, 1962), as described earlier (Tan et al., 2006b).

The almost complete 16S rRNA gene sequences (1391$1465 \mathrm{nt}$ ) generated by Tan et al. (2006a) were aligned manually against corresponding sequences of the type 
strains of species of the genus Amycolatopsis retrieved from GenBank/EMBL/DDBJ databases using the PHYDIT program (http://plaza.snu.ac.kr/ jchun/phydit). Phylogenetic trees were inferred by using the maximum-likelihood (Felsenstein, 1981), maximum-parsimony (Fitch, 1971) and neighbour-joining (Saitou \& Nei, 1987) tree-making algorithms drawn from the MEGA4 (Tamura et al., 2007) and PHYML (Guindon \& Gascuel, 2003) packages; an evolutionary distance matrix for the neighbour-joining algorithm was generated using the Jukes \& Cantor (1969) model. The topologies of the evolutionary trees were evaluated by a bootstrap analysis (Felsenstein, 1985) of the neighbour-joining method based upon 1000 replicates using the MEGA4 program. The root position of the Amycolatopsis tree based on the neighbour-joining algorithm was inferred, using Prauserella rugosa DSM $43194^{\mathrm{T}}$ (GenBank accession no. AF051342) as the outgroup.

Phylogenetic analysis revealed that the two isolates formed a group within the A. methanolica $16 \mathrm{~S}$ rRNA subclade, and this was supported by all of the tree-making algorithms and by a bootstrap value of $72 \%$ (Fig. 1). This taxon is most closely related to a corresponding group composed of the type strains of A. methanolica and A. thermoflava. The isolates shared a 16S rRNA gene similarity of $98.2 \%$, a value which corresponded to $25 \mathrm{nt}$ differences at 1385 locations. Isolate $\mathrm{GY} 088^{\mathrm{T}}$ appears most closely related to the type strain of $A$. thermoflava; the two organisms share a $16 \mathrm{~S}$ rRNA gene similarity of $98.3 \%$, a value equivalent to $24 \mathrm{nt}$ differences at 1429 locations. Similarly, strain GY115 appears closely related to the type strains of $A$. methanolica and $A$. thermoflava, sharing $98.6 \%$ similarity with them, a value corresponding to $20 \mathrm{nt}$ differences at 1389 and 1388 locations, respectively. DNA-DNA relatedness studies of these strains were not carried out because the levels of $16 \mathrm{~S}$ rRNA gene sequence similarity between the strains were lower than those between the other organisms assigned to the A. methanolica subclade. The type strains of $A$. methanolica and A. thermoflava, for instance, share a $16 \mathrm{~S}$ rRNA gene sequence similarity of $99.8 \%$, with a corresponding DNA-DNA relatedness score of only $21 \%$ (Chun et al., 1999) - a value well below the $70 \%$ cut-off point recommended for assigning strains to the same genomic species (Wayne et al., 1987). The corresponding DNA-DNA relatedness score between the type strains of Amycolatopsis eurytherma and Amycolatopsis tucumanensis is $39.5 \%$, and these organisms share a $16 \mathrm{~S}$ rRNA gene sequence similarity of $99.9 \%$ (Albarracín et al., 2010).

The isolates were examined for chemical markers to establish whether they had a chemotaxonomic profile typical of members of the genus Amycolatopsis. Standard procedures were used to determine the isomers of diaminopimelic acid $\left(\mathrm{A}_{2} \mathrm{pm}\right)$ (Staneck \& Roberts, 1974), menaquinones (Minnikin et al., 1984), muramic acid type (Uchida et al., 1999), sugars (Schaal, 1985) and polar lipids (Minnikin et al., 1984), using the type strains of A. methanolica and A. thermoflava as controls. Each of the isolates contained meso- $\mathrm{A}_{2} \mathrm{pm}$, arabinose and galactose in whole-organism hydrolysates (wall chemotype IV, sensu Lechevalier \& Lechevalier, 1970); $\mathrm{N}$-acetylated muramic acid, tetrahydrogenated menaquinones with nine isoprene units as the predominant isoprenologue $(>96 \%)$ and major amounts of diphosphatidylglycerol, phosphatidylethanolamine, phosphatidylmethylethanolamine, phosphatidylglycerol and phosphatidylinositol (phospholipid pattern II sensu Lechevalier et al., 1977). These data are in line with the

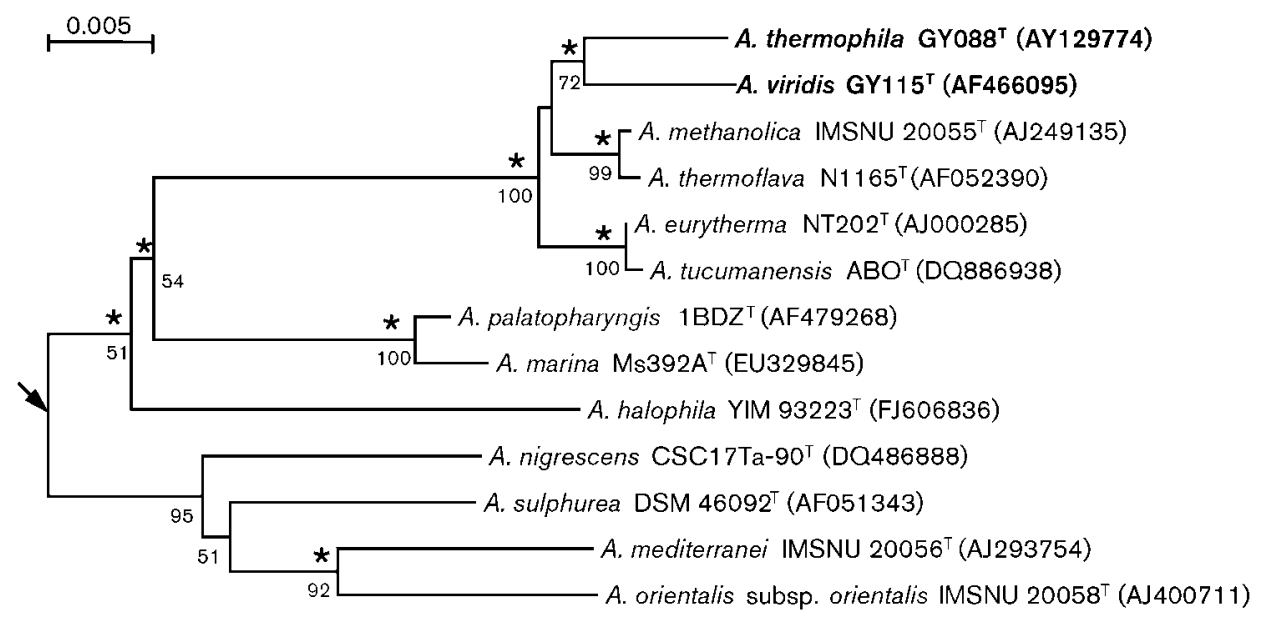

Fig. 1. Neighbour-joining (Saitou \& Nei, 1987) phylogenetic tree based on almost complete 16S rRNA gene sequences (>1385 nt), showing relationships between isolates $\mathrm{GYO88}^{\top}$ and $\mathrm{GY} 115^{\top}$ and between them and representatives of the closest related species of the genus Amycolatopsis. Asterisks indicate branches of the tree that were also found using the maximum-likelihood (Felsenstein, 1981) and maximum-parsimony (Fitch, 1971) tree-making algorithms. Numbers at the nodes indicate the levels of bootstrap support (\%) based on a neighbour-joining analysis of 1000 resampled datasets; only values above $50 \%$ are given. The arrow indicates the inferred root position, using Prauserella rugosa DSM $43194^{\top}$ (GenBank accession no. AF051342) as outgroup. Bar, 0.005 substitutions per nucleotide position. 
classification of the isolates in the genus Amycolatopsis (Lechevalier et al., 1986; Lee, 2009).

The isolates, together with the type strains of A. eurytherma, A. methanolica, A. thermoflava and A. tucumanensis, were examined in a range of phenotypic tests known to be of value in the systematics of the genus Amycolatopsis (De Boer et al., 1990; Goodfellow et al., 2001; Tan et al., 2006b, 2007). All of the strains were Gram-positive-staining, non-acid-alcoholfast, formed a branched substrate mycelium that fragmented into coccoid and rod-like elements on oatmeal agar, grew well at $50{ }^{\circ} \mathrm{C}$ and produced acid from cellobiose and xylose. Nevertheless, all of the strains can be distinguished using a combination of phenotypic features (Table 1). Isolate $\mathrm{GY} 115^{\mathrm{T}}$ can readily be distinguished from isolate $\mathrm{GY} 088^{\mathrm{T}}$ as it forms white aerial hyphae on oatmeal agar, produces acid from L-arabinose, galactose, lactose, salicin and trehalose, and degrades tyrosine but is unable to reduce nitrate or degrade casein, elastin or gelatin.

It is evident from the genotypic and phenotypic data that the two isolates can be readily distinguished from one another and from the other thermophilic strains classified in the A. methanolica 16S rRNA subclade. It is, therefore, proposed that isolates $\mathrm{GY} 088^{\mathrm{T}}$ and $\mathrm{GY} 115^{\mathrm{T}}$ be classified in the genus Amycolatopsis, as Amycolatopsis thermophila sp. nov. and Amycolatopsis viridis sp. nov., respectively.

All of the tested strains grew well at $50{ }^{\circ} \mathrm{C}$ on GYE agar and can thereby be considered to be thermophilic actinomycetes (Cross, 1968; Brock, 1986). Further comparative studies between members of the A. methanolica subclade

Table 1. Diagnostic characteristics that differentiate strains $G Y 088^{\top}$ and $G Y 115^{\top}$ from one another and from their closest phylogenetic relatives in the genus Amycolatopsis

Strains: 1 , GY088 ${ }^{\mathrm{T}}$; 2, GY $115^{\mathrm{T}}$; 3, A. eurytherma DSM $44348^{\mathrm{T}}$; 4, A. methanolica KCTC $9411^{\mathrm{T}}$; 5 , A. thermoflava KCTC $9833^{\mathrm{T}}$; 6, A. tucumanensis $\mathrm{ABO}^{\mathrm{T}}$. +, Positive; -, negative; $\mathrm{w}$, weakly positive.

\begin{tabular}{|c|c|c|c|c|c|c|}
\hline Characteristic & 1 & 2 & 3 & 4 & 5 & 6 \\
\hline \multicolumn{7}{|c|}{ Morphological properties on oatmeal agar: } \\
\hline Formation/colour of aerial hyphae & - & White & White & White & White & - \\
\hline Colour of substrate mycelium & Yellow-brown & Yellow-green & Yellow & Yellow & Yellow & Yellow \\
\hline Production of soluble pigment & - & - & - & - & + & - \\
\hline \multicolumn{7}{|l|}{ Acid from: } \\
\hline$(+)$-L-Arabinose & - & + & + & + & + & + \\
\hline Dextrin & - & - & $\mathrm{W}$ & - & - & - \\
\hline meso-Erythritol & - & - & + & - & + & + \\
\hline$(+)$-D-Galactose & - & + & + & + & + & + \\
\hline myo-Inositol & - & - & + & - & - & - \\
\hline$(+)$-D-Lactose & - & + & $\mathrm{w}$ & + & + & + \\
\hline (-)-D-Mannitol & - & - & + & - & + & + \\
\hline$(+)$-D-Melibiose & - & - & - & - & + & - \\
\hline Methyl $\alpha$-D-glucoside & - & - & - & - & + & + \\
\hline$(+)$-D-Raffinose & - & - & - & + & + & + \\
\hline$(+)$-D-Ribose & - & - & - & + & + & - \\
\hline (-)-D-Sorbitol & - & - & + & + & + & + \\
\hline$(-)$-D-Sucrose & - & - & - & + & - & + \\
\hline$(+)$-D-Trehalose & - & + & + & + & + & - \\
\hline$(+)$-D-Xylose & - & - & + & + & + & + \\
\hline \multicolumn{7}{|l|}{ Hydrolysis of: } \\
\hline Aesculin & - & - & - & + & + & + \\
\hline Allantoin & - & - & + & - & + & - \\
\hline Nitrate & + & - & + & + & - & - \\
\hline Urease & - & - & + & - & + & - \\
\hline \multicolumn{7}{|l|}{ Degradation of: } \\
\hline Casein & + & - & + & + & + & + \\
\hline Elastin & + & - & + & + & + & + \\
\hline Gelatin & + & - & + & + & + & + \\
\hline Hypoxanthine & - & + & $\mathrm{w}$ & + & + & - \\
\hline Starch & + & + & - & - & - & + \\
\hline Tyrosine & - & + & + & + & + & - \\
\hline Xanthine & + & + & - & + & - & - \\
\hline Growth at $10{ }^{\circ} \mathrm{C}$ & + & + & - & + & - & - \\
\hline
\end{tabular}


and those of the other Amycolatopsis subclades are needed, to determine whether the former merits generic status.

\section{Description of Amycolatopsis thermophila sp. nov.}

Amycolatopsis thermophila (ther.mo'phi.la. Gr. n. thermê heat; Gr. fem. adj. philê loving; N.L. fem. adj. thermophila heat-loving organism).

Aerobic, Gram-positive-staining, non-acid-alcohol-fast, non-motile, catalase-positive actinomycete that forms a pale yellow to brown substrate mycelium that fragments into coccoid to rod-shaped elements when grown on modified Bennett's agar supplemented with mannitol and soybean flour. Neither aerial hyphae nor diffusible pigments are formed on this medium. Grows at 10 and $50{ }^{\circ} \mathrm{C}$ and from pH 5.0 to 10.0. Xylan is degraded, but not xanthine. Grows in the presence of $\left(\mu \mathrm{g} \mathrm{ml}^{-1}\right)$ neomycin sulphate (4), penicillin G (20) and rifampicin (10), but is sensitive to gentamicin sulphate (5), neomycin sulphate (8), streptomycin sulphate (10), novobiocin (10) and vancomycin hydrochloride (10). Lysozyme $(0.005 \%, \mathrm{w} / \mathrm{v})$ sensitive. Results of additional phenotypic tests are cited in the text and in Table 1. Chemotaxonomic properties are typical of the genus.

The type strain GY088 ${ }^{\mathrm{T}}\left(=\mathrm{NCIMB} 14699^{\mathrm{T}}=\right.$ NRRL B-24836 $\left.{ }^{\mathrm{T}}\right)$ was isolated from an arid composite Australian soil sample. The species description is based on a single strain, which hence serves as the type strain.

\section{Description of Amycolatopsis viridis sp. nov.}

Amycolatopsis viridis (vi'ri.dis. L. fem. adj. viridis green, referring to the production of a greenish substrate mycelium).

Aerobic, Gram-positive-staining, non-acid-alcohol-fast, non-motile, catalase-positive actinomycete that forms a medium yellow to green substrate mycelium that fragments into coccoid to rod-like elements, but which does not produce diffusible pigments on modified Bennett's agar supplemented with mannitol and soybean flour. Abundant white, sterile aerial hyphae are produced. Grows at 10 and $50{ }^{\circ} \mathrm{C}$ and from pH 5.0 to 10.0. Degrades hypoxanthine, uric acid and xylan, but not arbutin. Grows in the presence $\left(\mu \mathrm{g} \mathrm{ml}^{-1}\right.$ ) of gentamicin sulphate (5), neomycin sulphate (8), novobiocin (10), rifampicin (10), tobramycin sulphate (8) and vancomycin hydrochloride (10), but is susceptible to penicillin $\mathrm{G}(20)$ and streptomycin sulphate (16). Lysozyme $(0.005 \%, w / v)$ sensitive. Additional phenotypic properties are cited in the text and in Table 1. Chemotaxonomic properties are typical of the genus.

The type strain GY$_{115^{\mathrm{T}}} \quad\left(=\mathrm{NCIMB} \quad 14700^{\mathrm{T}}=\mathrm{NRRL}\right.$ B-24837 $)$ was isolated from an arid composite Australian soil sample. The species description is based on a single strain, which hence serves as the type strain.

\section{Acknowledgements}

T.D.Z. is indebted to the Conselho Nacional de Desenvolvimento Científico e Tecnológico for a fellowship to study in the UK (grant
201066/2009-2). We are also grateful to Dr Martha Trujillo (University of Salamanca) for the gift of the type strain of $A$. tucumanensis.

\section{References}

Albarracín, V. H., Alonso-Vega, P., Trujillo, M. E., Amoroso, M. J. \& Abate, C. M. (2010). Amycolatopsis tucumanensis sp. nov., a copperresistant actinobacterium isolated from polluted sediments. Int J Syst Evol Microbiol 60, 397-401.

Bian, J., Li, Y., Wang, J., Song, F. H., Liu, M., Dai, H. Q., Ren, B., Gao, H., Hu, X. \& other authors (2009). Amycolatopsis marina sp. nov., an actinomycete isolated from an ocean sediment. Int J Syst Evol Microbiol 59, 477-481.

Brock, T. D. (1986). Introduction: an overview of the thermophiles. In Thermophiles: General, Molecular and Applied Microbiology, pp. 1-11. Edited by T. D. Brock. New York: John Wiley \& Sons.

Chun, J., Kim, S. B., Oh, Y. K., Seong, C. N., Lee, D. H., Bae, K. S., Lee, K. J., Kang, S. O., Hah, Y. C. \& Goodfellow, M. (1999). Amycolatopsis thermoflava sp. nov., a novel soil actinomycete from Hainan Island, China. Int J Syst Bacteriol 49, 1369-1373.

Cross, T. (1968). Thermophilic actinomycetes. J Appl Bacteriol 31, 36-53.

De Boer, L., Dijkhuizen, L., Grobben, G., Goodfellow, M., Stackebrandt, E., Parlett, J. H., Whitehead, D. \& Witt, D. (1990). Amycolatopsis methanolica sp. nov., a facultatively methylotrophic actinomycete. Int J Syst Bacteriol 40, 194-204.

Felsenstein, J. (1981). Evolutionary trees from DNA sequences: a maximum likelihood approach. J Mol Evol 17, 368-376.

Felsenstein, J. (1985). Confidence limits on phylogenies: an approach using the bootstrap. Evolution 39, 783-791.

Fitch, W. M. (1971). Toward defining the course of evolution: minimum change for specific tree topology. Syst Zool 20, 406-416.

Goodfellow, M., Kim, S. B., Minnikin, D. E., Whitehead, D., Zhou, Z.-H. \& Mattinson-Rose, A. D. (2001). Amycolatopsis sacchari sp. nov., a moderately thermophilic actinomycete isolated from vegetable matter. Int J Syst Evol Microbiol 51, 187-193.

Gordon, R. E. \& Mihm, J. M. (1962). Identification of Nocardia caviae (Erikson) nov. comb. Ann N Y Acad Sci 98, 628-636.

Guindon, S. \& Gascuel, O. (2003). A simple, fast, and accurate algorithm to estimate large phylogenies by maximum likelihood. Syst Biol 52, 696-704.

Huang, Y., Paściak, M., Liu, Z., Xie, Q. \& Gamian, A. (2004). Amycolatopsis palatopharyngis sp. nov., a potentially pathogenic actinomycete isolated from a human clinical source. Int J Syst Evol Microbiol 54, 359-363.

Jones, K. L. (1949). Fresh isolates of actinomycetes in which the presence of sporogenous aerial mycelia is a fluctuating characteristic. J Bacteriol 57, 141-145.

Jukes, T. H. \& Cantor, C. R. (1969). Evolution of protein molecules. In Mammalian Protein Metabolism, vol. 3, pp. 21-132. Edited by H. N. Munro. New York: Academic Press.

Kim, B., Sahin, N., Tan, G. Y. A., Zakrzewska-Czerwinska, J. \& Goodfellow, M. (2002). Amycolatopsis eurytherma sp. nov., a thermophilic actinomycete isolated from soil. Int J Syst Evol Microbiol 52, 889-894.

Labeda, D. P., Donahue, J. M., Williams, N. M., Sells, S. F. \& Henton, M. M. (2003). Amycolatopsis kentuckyensis sp. nov., Amycolatopsis lexingtonensis sp. nov. and Amycolatopsis pretoriensis sp. nov., isolated from equine placentas. Int J Syst Evol Microbiol 53, 1601-1605. 
Labeda, D. P., Goodfellow, M., Chun, J., Zhi, X. Y. \& Li, W. J. (2011). Reassessment of the systematics of the suborder Pseudonocardineae: transfer of the genera within the family Actinosynnemataceae Labeda and Kroppenstedt 2000 emend. Zhi et al. 2009 into an emended family Pseudonocardiaceae Embley et al. 1989 emend. Zhi et al. 2009. Int J Syst Evol Microbiol 61, 1259-1264.

Lechevalier, M. P. \& Lechevalier, H. (1970). Chemical composition as a criterion in the classification of aerobic actinomycetes. Int J Syst Bacteriol 20, 435-443.

Lechevalier, M. P., De Biévre, C. \& Lechevalier, H. (1977). Chemotaxonomy of aerobic actinomycetes: phospholipid composition. Biochem Syst Ecol 5, 249-260.

Lechevalier, M. P., Prauser, H., Labeda, D. P. \& Ruan, J.-S. (1986). Two new genera of nocardioform actinomycetes: Amycolata gen. nov. and Amycolatopsis gen. nov. Int J Syst Bacteriol 36, 29-37.

Lee, S. D. (2009). Amycolatopsis ultiminotia sp. nov., isolated from rhizosphere soil, and emended description of the genus Amycolatopsis. Int J Syst Evol Microbiol 59, 1401-1404.

Minnikin, D. E., O'Donnell, A. G., Goodfellow, M., Alderson, G., Athalye, M., Schaal, A. \& Parlett, J. H. (1984). An integrated procedure for the extraction of bacterial isoprenoid quinones and polar lipids. J Microbiol Methods 2, 233-241.

Saitou, N. \& Nei, M. (1987). The neighbor-joining method: a new method for reconstructing phylogenetic trees. Mol Biol Evol 4, 406-425.

Schaal, K. P. (1985). Identification of clinically significant actinomycetes and related bacteria using chemical techniques. In Chemical Methods in Bacterial Systematics, pp. 359-381. Edited by M. Goodfellow \& D. E. Minnikin. London: Academic Press.

Staneck, J. L. \& Roberts, G. D. (1974). Simplified approach to identification of aerobic actinomycetes by thin-layer chromatography. Appl Microbiol 28, 226-231.
Tamura, K., Dudley, J., Nei, M. \& Kumar, S. (2007). MEGA4: molecular evolutionary genetics analysis (MEGA) software version 4.0. Mol Biol Evol 24, 1596-1599.

Tan, G. Y. A., Ward, A. C. \& Goodfellow, M. (2006a). Exploration of Amycolatopsis diversity in soil using genus-specific primers and novel selective media. Syst Appl Microbiol 29, 557-569.

Tan, G. Y. A., Robinson, S., Lacey, E. \& Goodfellow, M. (2006b). Amycolatopsis australiensis sp. nov., an actinomycete isolated from arid soils. Int J Syst Evol Microbiol 56, 2297-2301.

Tan, G. Y. A., Robinson, S., Lacey, E., Brown, R., Kim, W. \& Goodfellow, M. (2007). Amycolatopsis regifaucium sp. nov., a novel actinomycete that produces kigamicins. Int J Syst Evol Microbiol 57, 2562-2567.

Tseng, M., Yang, S.-F., Li, W.-J. \& Jiang, C.-L. (2006). Amycolatopsis taiwanensis sp. nov., from soil. Int J Syst Evol Microbiol 56, 1811-1815.

Uchida, K., Kudo, T., Suzuki, K. I. \& Nakase, T. (1999). A new rapid method of glycolate test by diethyl ether extraction, which is applicable to a small amount of bacterial cells of less than one milligram. J Gen Appl Microbiol 45, 49-56.

Wayne, L. G., Brenner, D. J., Colwell, R. R., Grimont, P. A. D., Kandler, O., Krichevsky, M. I., Moore, L. H., Moore, W. E. C., Murray, R. G. E. \& other authors (1987). International Committee on Systematic Bacteriology. Report of the ad hoc committee on the reconciliation of approaches to bacterial systematics. Int J Syst Bacteriol 37, 463-464.

Wink, J. M., Kroppenstedt, R. M., Ganguli, B. N., Nadkarni, S. R., Schumann, P., Seibert, G. \& Stackebrandt, E. (2003). Three new antibiotic producing species of the genus Amycolatopsis, Amycolatopsis balhimycina sp. nov., A. tolypomycina sp. nov., A. vancoresmycina sp. nov., and description of Amycolatopsis keratiniphila subsp. keratiniphila subsp. nov. and A. keratiniphila subsp. nogabecina subsp. nov. Syst Appl Microbiol 26, 38-46. 